The Economics and Finance Letters

2021 Vol. 8, No. 2, pp. 266-276.

$\operatorname{ISSN}(e): 2312-430 \mathrm{X}$

$\operatorname{ISSN}(p): 2312-6310$

DOI: 10.18488/journal.29.2021.82.266.276

(C) 2021 Conscientia Beam. All Rights Reserved.

check for
updates

\title{
OPTIMAL CONSUMPTION AND PORTFOLIO CHOICE: THE IMPACT OF HEALTH AND HEALTH RISK
}

You Du

\author{
Assistant Professor of Economics, Department of Economics, Finance and \\ Accounting, Fort Hays State University, USA. \\ Email:julie.du@fhsu.edu Tel:2672058488
}

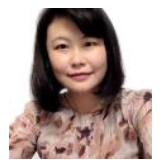

\section{ABSTRACT}

This paper investigates the effect of health and health risk on households' optimal consumption and portfolio allocations over the life cycle. The simulation results show that consumption, savings in bonds, and savings in stocks all increase in health. Compared with poor health households, the healthy households consume $49 \%$ higher, invest $27 \%$ and $39 \%$ more in bonds and in stocks, respectively. The risky portfolio share, which is the ratio of stocks to the total financial assets is positively related with health for most of the lifetime. Regarding the age profile, it demonstrates the same tendency for both health levels: at the very young age, the risky portfolio share is relatively high. Starting from the middle age, this share falls significantly and keeps steady until the end of life. These results emphasize the importance of health and its associated risk in consumption and portfolio decisions. With all other things equal, households' consumption and investment behaviors are heterogenous across health. It also provides significant policy applications: by promoting health and reducing health risk, it would largely improve households' well-being: higher consumption, and more savings in financial assets.

Contribution/Originality: This study is one of very few studies which incorporate health and its associated risk into households' consumption and financial decisions. This paper contributes to a new and growing financehealth literature and finds significant impacts of health and health risk on households' optimal consumption and portfolio allocations.

\section{INTRODUCTION}

How do people allocate their consumption and financial assets in their lifetime? Are health and its associated risk important determinants to be taken into account when making these decisions? If so, to what extent do health variables have effects on consumption and portfolio decisions? This paper aims to answer these questions in a life cycle framework. Better understanding these questions is useful to analyze and forecast households' life profile behavior and provide important policy implications.

The modern idea of investigating households' consumption and saving decisions was originally introduced by John Maynard Keynes in his most famous work "The General Theory of Employment, Interest and Money" in 1936. Since then, there has been a significantdevelopment in the literature examining how labor income and labor income risk affect households' optimal consumption, saving and portfolio decisions. Of course, labor income risk is an important factor to be considered when the consumption and portfolio decision 
are made. However, it is not the only substantial risk that people face in their lives. Health and health risk also have crucial influences on households' utility, welfare and financial allocations. This idea has been widely accepted by economists since (Grossman, 1972) the seminal work in the field of health economics. Even though labor income and labor income risk in explaining the consumption and portfolio allocation have received a lot of attention, there is very limited theoretical work on households' life cycle consumption and portfolio choices when they face uncertainty from income and from health. This motivates me to visit the topic and to further investigate to fill this gap.

I develop a quantitative life cycle model and solve numerically for a finite lived representative household's optimal consumption and financial allocations with income uncertainty and health risk. The model assumes that a household enters the model with an initial financial wealth endowment and initial health state. Every period, it faces income shock and health shock. After these shocks are realized, the household chooses consumption, savings in risk free bonds and savings in risky stocks to maximize its expected lifetime utility. I solve this life cycle model by using backward induction and a grid search method, a widely used methodology to solve finite horizon models.

I find that consumption, savings in bonds and savings in stocks all increase in health. The risky portfolio shares, which is the ratio of saving in stocks to the total financial assets, is positively related with health for most of the life cycle. Regarding the portfolio choice overtime, it shows the same shape across health during the life cycle: at the very young ages, the risky portfolio share is high. Starting from middle age, this share falls significantly and steadily until the end of life. These results emphasize the importance of health and health risk in consumption and portfolio decisions. All other things equal, households' consumption and investment behaviors are heterogenous across health.

This paper contributes to a new and growing finance-health literature with several highlights. First, the model introduces two mechanisms of how health impacts household's consumption decision. In this model, health directly enters the household's utility and therefore affects themarginal utility of consumption. Health and consumption are considered as substitutes inthe sense that the marginal utility of consumption is higher when health is poor. For example, the marginal consumption of physical therapy is high for an injured person. I call it the "substitute effect". Another mechanism is that health influences consumption through productivity and budget constraint. Poor health limits the household's productivity and results in a decline of labor income in the working stage, and lowering retirement income as well. This is the "income effect". Unlike most related literature in which the labor income process excludes health variables, this model captures the effect of health on the household's labor income process. The labor income process in this model is defined as a function of age, health status and productivity shock. The retirement income is defined as a fixed fraction of the last working year's income. Therefore, it also depends on the household's health status. In addition, this paper extends the existing finance-health literature — which mainly focuses on retirees' decisions-by incorporating working-stage decisions. These two mechanisms-the "substitute effect" and "income effect"-work oppositely and alter the household's optimal consumption decision.

Second, health risk, which could be considered as a "background risk", generate fluctuations in utility and in productivity. This influences the household's attitude towards risky assets. First, because in this model health status directly enters household's preference, a health shock that causes health volatility also increases the degree of fluctuation in utility. Thus, a typical risk averse household will choose to save more in risk-free assets. Second, health risk causes volatility in household's income, which could amplify income and budget uncertainty. With the combination of health risk and income risk, the household would optimally re-allocate his financial assets. 


\section{LITERATURE REVIEW}

A large body of modern literature in the field of households' optimal consumption, saving and portfolio choices can be traced back to as early as 1936. In John Maynard Keynes' most famous book "The General Theory of Employment, Interest and Money", he first developed the concept of households' consumption and saving decisions in a formal economics way. In modern macroeconomics, the life cycle model is a standard method to investigate intertemporal decisions of consumption, saving and portfolio allocation, taking multidimension risks into account. This approach has a history back to 1928 with the infinite horizon model of Ramsey and the finite horizon model of Fisher in 1930.

After the development in the 1950s-Friedman (1957) with the infinite horizon model Modigliani and Brumberg (1954) with the finite horizon model-Hall made the next notable contribution in developing life cycle models in 1978. Hall employed a finite horizon life cycle model with income risk and used the Euler equation to solve for the optimal consumption problem. Theoretically, the Euler equation method seems feasible. "In practice, however, this approach does not work unless the number of periods is relatively small." Niku (2014) the reason lies in that when the number of periods raises, the number of shocks, unidentified variables and equations all increase exponentially that it is impossible to solve the problem with hand. Fortunately these multi-period problems with uncertainty can be overcome by describing the household's problem with recursive Bellman equations and be solved as dynamic programming. In 1989, Zeldes first used the computer technology to solve consumption andsaving problem in a life cycle model with labor income risk for 15 periods. After that, therehave been prominent developments of dynamic programming in macroeconomics field, and alarge body of literature uses backward induction and numerical method to study households'consumption, saving and portfolio choices in the working stage when they face labor income risk.

The most influential literature of consumption and saving models with income risk includes Deaton (1991); Hubbard, Skinner, and Zeldes (1994) and Carroll (1997). Several papers extend to study the effects of labor income risk on portfolio allocation during the working phase. "Heaton and Lucas (1997); Koo (1998) and Viceira (2001) consider infinite-horizon models of portfolio choice with uninsurable labor income risk.” Cocco, Gomes, and Maenhout (2005).

However, these infinite horizon models are less realistic and less suitable to explore decisions of household's life profile with finite horizon. Bertaut and Haliassos (1997); Davis and Willen (2013) adopt finite horizon models to evaluate the portfolio decision. Cocco et al. (2005) develops a life cycle model of consumption and portfolio choice with labor income risk and investigates the effect of this income risk on a representative household's financial investment behavior.

Meanwhile, the idea that health is an essential type of human capital with significant effect for a household's utility, welfare and social economics status has been widely acceptedby economists. Some papers in the 1960's have suggest that health can be considered as one form of human capital (Becker, 1964; Mushkin, 1962). Grossman (1972) develops a model of the demand for health, which is considered as a benchmark work in health economics. Since then, a branch of literature explores households' consumption, saving and portfolio decisions in the life cycle model with health related variables. However, in this field, most of the studies focus on the retirees' problems. Some papers analyze the effect of a retiree's health expenditures on savings focusing on the very old age households. However, they don't investigate optimal portfolio allocation (De Nardi, French, \& Jones, 2010; Kopecky \& Koreshkova, 2014). Some literature studies financial assets allocation between stocks, bonds and annuity with exogenous medical spending for the elderly (Koijen, Van Nieuwerburgh, \& Yogo, 2016; Pang \& Warshawsky, 2010). Yogo (2016) analyzes retirees' financial portfolio decisions with health risk, financial risk and housing price risk, but he also excludes the working stage.

Besides structural models, there are also some empirical studies examining the effects of health status and medical expenditures on savings and portfolio choices. Rosen and $\mathrm{Wu}$ (2004) indicates that health is a 
significant factor when a household makes financial decisions by using the Health and Retirement Study. Edwards (2008) shows the effect of risky health on explaining households' decreasing risky portfolio share after they get retired. Inkmann, Lopes, and Michaelides (2011) uses UK data to study the empirical causes of annuity demand with exogenous health expenditures.

\section{FULL MODEL}

This section describes the life cycle model of consumption and portfolio choice with health risk. The basic framework can be summarized as follows: a household enters the model with an initial endowment of financial wealth and health capital. In each period,it receives income, gross return of its financial assets and faces health risk and income uncertainty. After these risks realize, the household chooses consumption and allocates its financial wealth between risk free bonds and risky stocks in every period to maximize its expected lifetime utility.

\subsection{Time}

Time is discrete and each period refers to one year. A household enters the model when itis 25 years old. Its age is denoted as $t$. For example, $t=6$ indicates the household is 30 yearsold. Following the convention in the literature, the maximum of the life period is denoted as $T=60$, which means the household's maximum age is 84 years old. The household enters its retirement at age $K$. $K$ is exogenous and deterministic, i.e. $K$ $=40$ which implies the household retires at age 64 with certainty.

\subsection{Income}

The household works for the first $K-1$ periods of its life and receives labor income. After that, the household enters its retirement (from $K$ to $T$ ), in which it has retirement income.

\subsubsection{Labor Income Process in Working Phase}

Before retirement, at age $t$, a household receives labor income $\Upsilon_{t}(t<K)$, which is exogenously given by

$$
\Upsilon_{t}=f\left(t, H_{t}, Z_{t}\right)
$$

Equation 1 determines the household's labor income in the working periods, which depends on its age $t$, health

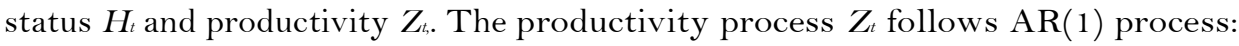

$$
Z_{t}=\rho Z_{t-1}+\mu_{t}
$$

In Equation 2, $\rho \in(0,1)$ is the coefficient of productivity persistence, and $\mu_{t}$ is an i.i.d normally distributed random variable with mean zero and variance $\sigma^{2}$. The current period productivity $Z_{t}$ depends on the previous productivity $Z_{t-1}$ and a random shock $\mu_{t}$. Then by using Tauchen method, this $\operatorname{AR}(1)$ continuous process is approximated through a discrete Markov-Chain which will mimic closely the underlying process. For simplicity, productivity $Z_{t}$ is discretized as two states, state $i$ and state $j$ (i.e. $Z_{t}=i$ means productivity is high and $Z_{t}=j$ means productivity is low) with a corresponding 2 by 2 transition matrix $\pi_{z}$. I denote the $(i, j)$ th element of transition matrix by:

$$
\pi_{z i j}=\operatorname{Pr}\left(Z_{t+1}=j / Z_{t}=i\right)
$$

Equation 3 means, if in the period $t$, productivity $Z_{t}$ is state $i$, then in the next period $t+1$, the probability of productivity $Z_{t+1}$ becoming state $j$ is the $(i, j)$ th element of transition matrix $\pi_{z}$.

\subsubsection{Income in Retirement Phase}

When the household enters retirement, its income $\Upsilon_{t}$ in period $t(K \leq t \leq T)$ is defined as a fixed fraction $\lambda \in(0,1)$ of the last working year's income $Y_{K-1}$ and its current health status $H_{t}$, which is given by:

$$
\Upsilon_{t}=g\left(\lambda \Upsilon_{K-1}, H_{t}\right)
$$


Equation 4 shows the household's retirement income.

\subsection{Health and Health Risk}

A household enters the model with an initial health state $H_{t}$, whose dynamic follows AR (1) Process:

$$
H_{t}=\varphi H_{t-1}+E_{t}
$$

In Equation 5, $\varphi \in(0,1)$ is the coefficient of health persistence. $E_{t}$ is an i.i.d normally distributed random variable with mean zero and variance $\sigma^{2}$. The current period health $H_{t}$ dependson the previous health $H_{t-1}$ and a random shock $E_{t}$. Similar to productivity $Z_{t}$, by using Tauchen method, this continuous process is approximated through a discrete finite-state Markov-Chain. For simplicity, health $H_{t}$ is discretized as two states, state $i$ and state $j$ (i.e. $H_{t}=i$ means health is good and $H_{t}=j$ means health is poor) with a corresponding 2 by 2 transition matrix $\pi_{H}$. The $(i, j)$ th element of transition matrix is defined as:

$$
\pi_{H} i_{j}=\operatorname{Pr}\left(H_{t+1}=j / H_{t}=\imath\right)
$$

Equation 6 indicates that, if in period $t$, health $H_{t}$ is state $i$, then in the next period $t+1$, the probability that health $H_{t_{+1}}$ is equal to state $j$ is the $(i, j)$ th element of transition matrix $\pi_{H}$.

In each period, after the health state $H_{t}$ is realized, it directly enters the household's utility function and also the income process.

\subsection{Budget Constraints}

Every period, the household receives income and gross return on its financial assets, and then decides how much to consume and how much to allocate in financial savings. For clarity, I name the state variables of financial wealth that the household holds as "asset in bonds $A b_{t}$ " and "asset in stocks $A s_{t}$ ". I denote the control variables of financial wealth that the household chooses as "savings in bonds $A b_{t+1}$ " and "savings in stocks $A s_{t+1}$ ". The budgetconstraint is

$$
C_{t}+A b_{t+1}+A s_{t+1}=A b_{t} R b_{t}+A s_{t} R s_{t}+Y_{t}
$$

In Equation 7, the left hand side is the sum of consumption $C_{t}$ in period $t$, savings in bonds and savingsin stocks in the next period $t+1$. The right hand side of Equation (7) is the household's cash on hand which could be used for consumption and savings. It is the sum of income $Y_{t}$ in period $t$ and the gross return of its financial assets holding i.e. $\left(A b_{t} R b_{t}+A s_{t} R s_{t}\right)$. $R b_{t}$ is the gross rate of return for bonds and $A b_{t} R b_{t}$ is the gross return from bonds. $R s_{t}$ is the gross rate of return for stocks, and $A s_{t} R s_{t}$ is the gross return from stocks.

Financial assets and consumption are assumed to be non-negative in every period. There is no borrowing in this model.

$$
0 \leq A b, A s, C, \forall t
$$

Equation 8 illustrates the non-negative assumptions for financial assets $\left(A b_{t}, A s_{t}\right)$ and consumption $C_{t}$.

\subsubsection{Return for Bonds}

$R b_{t}=\bar{R}_{b}$ denotes a constant gross rate of return for bonds. The bond return is calibrated to $\bar{R}_{b}=1.025$ annually, following (Yogo, 2016).

\subsubsection{Return for Stocks}

In this model, the gross rate of return for stocks $A s_{t}$ follows AR (1) process which is discretized as a Markov-Chain by using Tauchen method. For simplicity, stock return is discretized as two states, state $i$ and state $j$ (i.e. $R s_{t}=i$ means stock return is high and $R s_{t}=j$ means stock return is low) and with a corresponding 2 by 2 transition matrix $\pi_{R s}$. The $(i, j)$ th element of transition matrix is denoted as:

$$
\pi_{R s} i_{j}=\operatorname{Pr}\left(R s_{t+1}=j / R s_{t}=\imath\right)
$$


Equation 9 suggests, if at time $t$, stock return $R s_{t}$ is state $i$, then in the next period $t+1$, the probability of stock return $R s_{t+1}$ becoming state $j$ is the $(i, j)$ th element of transition matrix $\pi_{R s .}$

\subsection{Utility Function}

The utility function is one of the essential factors to study consumption and portfolio behavior. Many utility functions in the life cycle literature are "Constant Relative Risk Aversion" (CRRA) functions with a single good (i.e. consumption). The utility function in this model also follows a CRRA form, but incorporates two parts: consumption and health. This setup highlights the important value of health in examining optimal consumption and portfolio choices. Both consumption and health enter the utility function directly with different weights. The function is given by:

$$
U\left(C_{t}, H_{t}\right)=\frac{\left((1-\alpha) C_{t}+\alpha H_{t}\right)^{1-\sigma}}{1-\sigma}
$$

Equation 10 is the household's in-period utility function, where $\alpha \in(0,1)$ is the utility weight on health. (1- $\alpha)$ is the utility weight on consumption. $\sigma>1$ is the coefficient of risk averse.

In addition, this utility function implies health and consumption are substitutes in the sense that the marginal utility of consumption decreases in health.

$$
\Delta U_{t} / \Delta C_{t}=(1-\alpha)\left((1-\alpha) C_{t}+\alpha H_{t}\right)^{-\sigma}
$$

Equation 11 implies the marginal utility of consumption depends on both consumption $C_{t}$ and health $H_{t}$. For a given consumption level, if the state of health is poor, the marginal utility of consumption is relatively high. For example, the marginal utility of a physical spa or massage is higher for households with poor health than for those with good health.

\subsection{Household's Problem}

Formally, at age $t$, a household is characterized by five state variables $\left(H_{t}, A b_{t}, A s_{t}, \Upsilon_{t}, R s_{t}\right)$ : health status, asset in bonds, asset in stocks, income and gross rate of return for stocks. The household's problem could be written recursively as Bellman Equation:

$$
\begin{gathered}
V\left(H_{t}, A b_{t}, A s_{t}, Y_{t}, R s_{t}\right)=\max \left\{U\left(C_{t}, H_{t}\right)+\beta E V\left(H_{t+1}, A b_{t+1}, A s_{t+1}, Y_{t+1}, R s_{t+1}\right)\right\}(12) \\
\left(C_{t}, A b_{t+1}, A s_{t+1}\right)
\end{gathered}
$$

subject to

$$
\begin{gathered}
C_{t}=A b_{t} R b_{t}+A s_{t} R s_{t}+Y_{t}-A b_{t+1}-A s_{t+1} \\
H_{t}=\varphi H_{t-1}+E_{t}(14) \\
0 \leq A b_{t}, A s_{t}, C_{t}, \forall t \quad(15)
\end{gathered}
$$

Parameter $\beta \in(0,1)$ is the subjective discount factor. $E$ is the expectation operator.

In period $t$, the household of state $\left(H_{t}, A b_{t}, A s, Y_{t}, R s_{t}\right)$ chooses consumption $C_{t}$, savingin bonds $A b_{t+1}$ and savings in stocks $A s_{t+1}$ to maximizes the sum of two components in Equation 12. The first component is the period utility from consumption and health. The second component is the discounted expected future value function. Equation 13 is the budget constraint. Equation 14 presents the law of motion regarding health. Equation 15 presents the non-negative constraints for consumption and financial assets in every period.

\subsection{Model Parameters}

Table 1 below is the summary of this model's key parameters. 
Table-1. Summary of Parameters

\begin{tabular}{l|c|c}
\hline Description & Parameter & Value \\
\hline Retirement age & $\mathrm{K}$ & 40 \\
\hline Discount factor & $\beta$ & 0.96 \\
\hline Risk averse parameter & $\sigma$ & 5 \\
\hline Gross return for risk free assets & $\bar{R}_{b}$ & 1.025 \\
\hline Utility weight on health & $\alpha$ & 0.2 \\
\hline Fraction of retirement income to last workingyear's income & $\lambda$ & 0.8 \\
\hline Health transition matrix & $\pi_{H}$ & {$[0.95,0.05 ; 0.2,0.8]$} \\
\hline
\end{tabular}

\section{SIMULATION RESULTS}

This section presents the simulation results and the discussion. By using backward induction and numerical methods (See Appendix A), I solve this life cycle model and obtain the policy functions of consumption, savings in bonds and savings in stocks. Then I simulate the three shocks in the model, i.e. productivity shock, health shock and gross rate of return for stocks. After that, 10,000 individuals are simulated to track their behaviors on average.

Table 2 below shows the simulation results in terms of consumption: consumption increases in health. On average, the households with good health consume $49 \%$ (43.82 vs 29.26 ) more than the households with poor health. The difference in the consumption level across health is almost constant over life cycle. For both health states, consumption first increases at very young ages, and then remains stable for the remaining life.

Table-2. Consumption across health in the simulated model.

\begin{tabular}{c|c|c}
\hline Age & Poor Health & Good Health \\
\hline 25 & 13.89 & 21.12 \\
\hline 30 & 22.09 & 35.85 \\
\hline 35 & 29.82 & 48.50 \\
\hline 40 & 32.50 & 48.79 \\
\hline 45 & 33.60 & 49.14 \\
\hline 50 & 33.44 & 47.93 \\
\hline 55 & 33.12 & 47.21 \\
\hline 60 & 32.11 & 44.36 \\
\hline 65 & 30.44 & 46.11 \\
\hline 70 & 30.00 & 45.95 \\
\hline 75 & 30.84 & 47.04 \\
\hline Average & 29.26 & 43.82 \\
\hline
\end{tabular}

There are two channels through which health could affect consumption: the substitute effect and the income effect. In my model, consumption and health are considered as substitutes in the sense of marginal consumption decreasing in health. In this perspective, individuals with poor health are willing to consume more than the healthy households. On the other side, households with poor health receive less income and therefore less consumption, which is called income effect. Thus, households with poor health consume less than healthy households. Overall, the substitute effect and the income effect work in opposite directions. The simulation results show that in this model, the income effect dominates over the life cycle.

Savings in bonds increase in health over the life cycle, which is demonstrated in Table 3. On average, healthy households save $27 \%$ (78.3\% vs $61.6 \%$ ) higher in bonds than those with poor health. The difference of savings in bonds between two health states becomes smaller in the middle of the life cycle. The life cycle pattern of savings in bonds presents a hump-shaped curve and the shape isthe same across health. 
Table-3. Savings in bonds across health in the simulated model.

\begin{tabular}{c|c|c}
\hline Age & Poor Health & Good Health \\
\hline 25 & 0.001 & 1.89 \\
\hline 30 & 16.01 & 51.49 \\
\hline 35 & 50.80 & 79.49 \\
\hline 40 & 69.73 & 88.48 \\
\hline 45 & 76.14 & 91.09 \\
\hline 50 & 80.68 & 92.70 \\
\hline 55 & 82.34 & 93.91 \\
\hline 60 & 84.17 & 95.09 \\
\hline 65 & 80.38 & 95.21 \\
\hline 70 & 75.73 & 93.69 \\
\hline Average & 61.60 & 78.30 \\
\hline
\end{tabular}

Table 4 reveals that savings in stocks also increase in health over the life profile. Healthy people invest $39 \%$ higher in stocks (34.69 vs 25). The pattern of savings in stocks is also hump-shaped: they first increase, then stay at a relatively high level to finally decrease sharply at the end of the life cycle. The tendencies are the same across health. Savings in bonds and savings in stocks decrease at the very old age for both health states. One potential explanation is the lack of bequest motive, which should be the primary reason why households hold bonds and equity assets, especially as they age Yogo (2016).

Table-4. Savings in stocks across health in the simulated model.

\begin{tabular}{c|c|c}
\hline Age & Poor Health & Good Health \\
\hline 25 & 2.28 & 12.12 \\
\hline 30 & 18.21 & 27.59 \\
\hline 35 & 25.13 & 33.98 \\
\hline 40 & 27.79 & 37.62 \\
\hline 45 & 28.85 & 38.25 \\
\hline 50 & 29.67 & 38.97 \\
\hline 55 & 29.53 & 38.97 \\
\hline 60 & 30.12 & 39.25 \\
\hline 65 & 28.73 & 40.01 \\
\hline 70 & 27.67 & 39.15 \\
\hline 75 & 27.02 & 35.69 \\
\hline Average & 25 & 34.69 \\
\hline
\end{tabular}

Table 5 illustrates the simulated results regarding the risky portfolio share, which is defined as the ratio of savings in stocks to the total financial assets. The risky portfolio share presents the same pattern across health during the life cycle: when young, agents' risky portfolio share is high. As they age, this share decreases, which is consistent with the empirical evidence. There are two conflicting motivations when a household considers the demand for risky assets. On the one side, as a risk-averse agent, it is naturally reluctant to expose more risk in the financial market when he is already facing income risk and health uncertainty. On the other side, it wants to accumulate its wealth quickly, by participatingin the financial markets with higher expected stock returns. At the very young age $25^{1}$ for both health levels, households do not have much wealth that the risky portfolio shares are extremely high. This implies the second motivation is particularly strong and dominates the total effect. As they get older, more wealth has already been accumulated in their life cycle. Thus, the wealth motivation becomes much weaker, and the hedging motivation grows into the leading factor. Therefore, a significant risky share decline occurs at age 30 until age 40. After that, the share is almost flat until the end of life.

${ }^{1}$ The first time period in the model. 
Table-5. Risky portfolio share (\%) across health in the simulated model.

\begin{tabular}{c|c|c}
\hline Age & Poor Health & Good Health \\
\hline 25 & 99.96 & 86.52 \\
\hline 30 & 53.22 & 34.89 \\
\hline 35 & 33.09 & 29.94 \\
\hline 40 & 28.49 & 29.83 \\
\hline 45 & 27.48 & 29.57 \\
\hline 50 & 26.88 & 29.60 \\
\hline 55 & 26.39 & 29.38 \\
\hline 60 & 26.35 & 29.22 \\
\hline 65 & 26.33 & 29.59 \\
\hline 70 & 26.97 & 29.47 \\
\hline 75 & 28.07 & 28.24 \\
\hline
\end{tabular}

In respect to the risky portfolio share across health levels, for age 25 to age 35 , the risky share is higher for the households with poor health, who has a much stronger wealth accumulation motivation than the good health group. This is because of their lower income due to poor health. In the rest of life, the risky portfolio share is positively correlatedwith health, which is in line with the empirical literature (e.g. Rosen and $\mathrm{Wu}(2004))$. As people aged, the incentive of wealth accumulation declines, while the hedging risk motivation increases. For the households with good health, which could be considered as a type of safe asset, they are willing to take more risk in the financial markets than the poor health group.

\section{CONCLUSION}

In this paper, I study the impacts of health and health risk on households' consumption and portfolio choices. I explore this in the context of a life cycle model with a working stageand a retirement stage. My findings demonstrate that consumption, savings in bonds and savings in stocks all increase in health. The risky portfolio share increases with health in most of the life cycle (except for very young ages), which is consistent with the empirical literature. As of age profile, when young, the risky portfolio share is high. From the middle age, the risky share decreases and keeps almost steady in the rest of life. My paper highlights the significant of health and health risk on households' consumption, and financial decisions. If the unhealthy households could improve their health status, their overall well-beings would be promoted with higher consumption and more financial assets.

Funding: This study received no specific financial support.

Competing Interests: The author declares that there are no conflicts of interests regarding the publication of this paper.

\section{REFERENCES}

Becker, G. S. (1964). Human capital: A theoretical and empirical analysis with special reference to education. New York: National Bureau of Economic Research; distributed by Columbia University Press.

Bertaut, C. C., \& Haliassos, M. (1997). Precautionary portfolio behavior from a life-cycle perspective. Journal of Economic Dynamics and Control, 21(8-9), 1511-1542.

Carroll, C. D. (1997). Buffer-stock saving and the life cycle/permanent income hypothesis. The Quarterly Journal of Economics, 112(1), 1-55. Available at: https://doi.org/10.1162/003355397555109.

Cocco, J. F., Gomes, F. J., \& Maenhout, P. J. (2005). Consumption and portfolio choice over the life cycle. The Review of Financial Studies, 18(2), 491-533. Available at: https://doi.org/10.1093/rfs/hhio17.

Davis, S. J., \& Willen, P. (2013). Occupation-level income shocks and asset returns: Their covariance and implications for portfolio choice. The Quarterly Journal of Finance, 3(03no4), $1350011 . \quad$ Available at: https://doi.org/10.1142/S2010139213500110. 
De Nardi, M., French, E., \& Jones, J. B. (2010). Why do the elderly save? The role of medical expenses. Journal of Political Economy, 118(1), 39-75. Available at: https://doi.org/10.1086/651674.

Deaton, A. (1991). Saving and liquidity constraints. Econometrica, 59(5), 1221-1248. Available at: https://doi.org/10.2307/2938366.

Edwards, R. D. (2008). Health risk and portfolio choice. Journal of Business $\mathcal{E}^{2}$ Economic Statistics, 26(4), 472-485. Available at: https://doi.org/10.1198/073500107000000287.

Friedman, M. (1957). A theory of the consumption function. Princeton: Princeton University Press.

Grossman, M. (1972). On the concept of health capital and the demand for health. The Journal of Political Economy, 80(2), 223255. Available at: https://doi.org/10.1086/259880.

Heaton, J., \& Lucas, D. (1997). Market frictions, savings behavior, and portfolio choice. Macroeconomic Dynamics, 1(1), 76-101.

Hubbard, R. G., Skinner, J., \& Zeldes, S. P. (1994). Expanding the life-cycle model: Precautionary saving and public policy. The American Economic Review, 84(2), 174-179.

Inkmann, J., Lopes, P., \& Michaelides, A. (2011). How deep is the annuity market participation puzzle? The Review of Financial Studies, 24(1), 279-319. Available at: https://doi.org/10.1093/rfs/hhq080.

Koijen, R. S., Van Nieuwerburgh, S., \& Yogo, M. (2016). Health and mortality delta: Assessing the welfare cost of household insurance choice. The Journal of Finance, 71(2), 957-1010. Available at: https://doi.org/10.1111/jofi.12273.

Koo, H. K. (1998). Consumption and portfolio selection with labor income: A continuous time approach. Mathematical Finance, 8(1), 49-65. Available at: https://doi.org/10.1111/1467-9965.00044.

Kopecky, K. A., \& Koreshkova, T. (2014). The impact of medical and nursing home expenses on savings. American Economic Journal: Macroeconomics, 6(3), 29-72. Available at: https://doi.org/10.1257/mac.6.3.29.

Modigliani, F., \& Brumberg, R. (1954). Utility analysis and the consumption function: An interpretation of cross-section data. Franco Modigliani, 1(1), 388-436.

Mushkin, S. J. (1962). Health as an investment. Journal of Political Economy, 7O(5, Part 2), 129-157.

Niku, M. (2014). Introduction to Life Cycle Models with Idiosyncratic Uncertainty, Study Note.

Pang, G., \& Warshawsky, M. (2010). Optimizing the equity-bond-annuity portfolio in retirement: The impact of uncertain health expenses. Insurance: Mathematics and Economics, 46(1), 198-209. Available at: https://doi.org/10.1016/j.insmatheco.2009.08.009.

Rosen, H. S., \& Wu, S. (2004). Portfolio choice and health status. Journal of Financial Economics, 72(3), 457-484. Available at: https://doi.org/10.1016/s0304-405x(03)00178-8.

Viceira, L. M. (2001). Optimal portfolio choice for long-horizon investors with nontradable labor income. The Journal of Finance, 56(2), 433-470.

Yogo, M. (2016). Portfolio choice in retirement: Health risk and the demand for annuities, housing, and risky assets. Journal of Monetary Economics, 80, 17-34. Available at: https://doi.org/10.1016/j.jmoneco.2016.04.008.

\section{Appendix-A. Numerical Solution and Grid Search Method}

In this life cycle model, a household has a finite life period instead of an infinite horizon, which make the model more realistic. The model is solved using backward induction over a discretized state space. State variable health $H_{t}$, income $Y_{t}$, and gross stock return $R s_{t}$ are discretized into through Markov chain process with corresponding transition matrices. Financial assets of bonds $A b_{t}$ and stocks $A s_{t}$ are discretized into 60 and 50 grids separately and generated in logarithm space.

The model is solved from the last period $T$. The last period of life is deterministic, sothe policy functions in the last period are trivial: the household will consume all its wealth and leave no assets ${ }^{2}$.

\footnotetext{
${ }^{2}$ There is no bequest motivation.
} 
Therefore, the last period's value function corresponds to the utility function. This value could be used to calculate the policy functions in $T-1$ period and obtain the value function in period $T-1$. By doing this procedure, I could solve the model recursivelyuntil the first period.

The maximization of value function iteration step is done by using grid search method. The value function iteration algorithm follows the steps below:

- Step 1. As mentioned earlier, the state space is discretized into finite grids for all state variables.

- Step 2. Use the backward induction. The value function of $T+1$ is zero, i.e. $V_{T+1}=0$, and is used as the initial value. For the last period $T$, the optimal choice of $A b_{t+1}$ and $A s_{t+1}$ are both zero. According to the budget constraint, corresponding consumption could be determined at each grid of state variables. Thus, the value functions in the last period $T$ are also determined for all the state grids.

- Step 3. For the periods before last period, fix the current state variables $\left(A b_{t}, A s, \Upsilon_{t}, R s_{t}, H_{t}\right)$. I begin with the first element in each state variable vector.

- Step 4. For each possible choice in the control grids of saving in bonds $A b_{t+1}$ and saving in stocks $A s_{t+1}$, calculate $R_{t}=U\left(C, H_{t}\right)+\beta E V\left(A b_{t+1}, A s_{t+1}, Y_{t+1}, R s_{t+1}, H_{t+1}\right)$, where $R_{t}$ is a single period (period $\left.t\right)$ return function. $\Upsilon_{t+1}, R s_{t+1}$ and $H_{t+1}$ are taken expectation by using their corresponding transition matrices respectively. Consumption is determined by budget constraint, i.e. Equation (7). If consumption is negative for a particular $A b_{t+1}$ and/or $A s_{t+1}$, assign a large negative number to $R_{t}$ as a penalty.

- Step 5. Find the location of the maximum and the maximum of $R_{t}$ by choosing $A b_{t_{+1}}$ and $A s_{t_{+1}}$ in their own state spaces. Store this maximum as the corresponding element of the updated value function, $V$ $\left(A b_{t+1}, A s_{t+1}, Y_{t_{+1}}, R s_{t+1}, H_{t+1}\right)$. Specify the location of this maximizer as of the corresponding element in the policy vector.

- Step 6. Complete Step 3 through Step 5 for every grid of state space $\left(A b, A s, X_{t}, R s, H_{t}\right)$ and then update value function and policy functions for a single period.

- Step 7. Update value function recursively from period $T$ until the first period byrepeating Step 3 to Step 6. Keep the corresponding elements in value function and policy functions for each period (from $t$ $=T$ to $t=1)$.

Views and opinions expressed in this article are the views and opinions of the author(s), The Economics and Finance Letters shall not be responsible or answerable for any loss, damage or liability etc. caused in relation to/arising out of the use of the content. 